\title{
Nitrogen containing hydrogenated amorphous carbon for thin-film field emission cathodes
}

\author{
Gehan A. J. Amaratunga ${ }^{a}$ \\ Department of Electrical Engineering and Electronics, University of Liverpool, P.O. Box 147, \\ Liverpool L69 3BX, United Kingdom \\ S. R. P. Silva \\ Department of Electronic and Electrical Engineering, University of Surrey, Guildford GU2 5XH, \\ United Kingdom
}

(Received 17 November 1995; accepted for publication 4 March 1996)

\begin{abstract}
Field emission measurements using $0.3 \mu \mathrm{m}$ thick nitrogen containing hydrogenated amorphous carbon films $(a-\mathrm{C}: \mathrm{H}: \mathrm{N})$ on $n^{++}-\mathrm{Si}$ cathodes are reported. Onset emission fields as low as $4 \mathrm{~V} \mu \mathrm{m}^{-1}$ have been obtained using a flat plate anode configuration. Uniform emission is observed over the entire cathode area at current densities below $7 \times 10^{-2} \mathrm{~mA} \mathrm{~cm}^{-2}$. At higher current density preferential emission from spots is observed. The spot emission is imaged using the ITO coated plate anode. A model based on the $a-\mathrm{C}: \mathrm{H}: \mathrm{N}$ acting as a space charge interlayer on the $n^{++}-\mathrm{Si}$ is proposed to explain the emission at low electric fields. (C) 1996 American Institute of Physics. [S0003-6951(96)01018-8]
\end{abstract}

Flat panel displays with the same picture quality as that available from conventional cathode ray tubes can, in principle, be obtained using multiple field emission cathodes placed close to the phosphor screen and addressing them appropriately. ${ }^{1}$ Diamond is a low electron affinity ${ }^{2}$ wide band-gap semiconductor, and, on certain crystalline surfaces can have a negative electron affinity if terminated with $\mathrm{H}^{2,3}$ or Cs. ${ }^{4}$ This makes it attractive as a field emission cathode material. It has been proposed ${ }^{5}$ that the electron affinity of diamond is largely determined by its local bonding environment. By analogy, amorphous carbon with a similar local bonding configuration to that of the diamond surface should also have a relatively low electron affinity. Photoelectron yield measurements on $a$-C:H (Ref. 6) do suggest wide bandgap $(>3.5 \mathrm{eV})$ polymeric $a-\mathrm{C}: \mathrm{H}$ has a low electron affinity.

Field emission has been measured on several carbon containing materials. Using rough or inhomogeneous materials Latham, ${ }^{7}$ Kordesh, ${ }^{8}$ Okano, ${ }^{9}$ have obtained emissions at field of $\sim 3 \mathrm{~V} \mu \mathrm{m}^{-1}$. Nitrogen containing single-crystal diamonds coated with $\mathrm{O}$ and $\mathrm{Cs}$ will emit at fields $<1 \mathrm{~V} \mu \mathrm{m} .^{4}$ For smooth homogeneous films high fields are usually necessary $\sim 10-20 \mathrm{~V} \mu \mathrm{m}^{-1} .{ }^{10}$ In this letter we report on an easily manufactured, smooth carbon and nitrogen containing film which can emit electrons at fields of $4 \mathrm{~V} \mu \mathrm{m}^{-1}$. Nitrogenation of $a-\mathrm{C}: \mathrm{H}$ has been investigated as there is growing evidence which shows that nitrogen acts as an $n$-type dopant in amorphous carbon ${ }^{11,12}$ and, therefore, has the potential of increasing the current density available from $a-\mathrm{C}: \mathrm{H}$ cathodes. The doping mechanism in $a-\mathrm{C}: \mathrm{H}: \mathrm{N}$ is somewhat complicated in that the donor level is not determined by a clearcut substitutional or interstitial bonding environment as in diamond. Rather in $a-\mathrm{C}: \mathrm{H}: \mathrm{N}$ the actual network changes to accommodate the $\mathrm{N}$. Theoretical models predict that the $\mathrm{N}$, in certain bonding environments ${ }^{13}$ can provide a donor level which is shallow with respect to the effective conduction band edge in $a-\mathrm{C}: \mathrm{H}: \mathrm{N}$ (which is modified from that in $a-\mathrm{C}: \mathrm{H}$

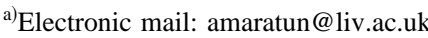

by the presence of $\mathrm{N}$ ). Experimental studies on the electrical properties of $a-\mathrm{C}: \mathrm{H}: \mathrm{N}$ carried out by us confirm that the variation in activation energy with increasing $\mathrm{N}$ is consistent with it acting as a donor ${ }^{12}$ but an inefficient one.

$a-\mathrm{C}: \mathrm{H}$ and $a-\mathrm{C}: \mathrm{H}: \mathrm{N}$ films were deposited from a $\mathrm{CH}_{4} / \mathrm{He} / \mathrm{N}_{2}$ gas mixture using a capacitively coupled rf PECVD apparatus with magnetic confinement. Magnetic confinement enables the formation of a dense plasma which is suitable for ionization of $\mathrm{N}_{2}$ and $\mathrm{N}$. Highly doped $n$-Si $(0.01-0.001 \Omega \mathrm{cm})$ was used as the substrate material and the back contact to the films. All depositions were carried out with the substrate holder held at a temperature of $20^{\circ} \mathrm{C}$. Details of deposition process can be found in the literature. ${ }^{14}$ The structure, composition, and bulk electronic properties of the films were examined using a number of methods. Electron energy loss spectroscopy (EELS) was used to determine film density. Film structure was determined by examination of the fine structure in the $\mathrm{C}$ and $\mathrm{N} k$-edge features obtained from EELS. The relative $\mathrm{N}$ content in the films was obtained from EELS, nuclear reaction analysis (NRA) and XPS: all three techniques giving similar values for $\mathrm{N}$ content. The $\mathrm{H}$ content was determined by electron recoil data analysis (ERDA) and RBS. Additionally, $I-V-T$ measurements (on films deposited under identical conditions on metal and quartz substrates) were also carried out to determine the influence of increasing the $\mathrm{N}$ content on resistivity. The results taken together suggest that, as in the case of unhydrogenated amorphous carbon, ${ }^{11} \mathrm{~N}$ acts as an electron donor in $a-\mathrm{C}: \mathrm{H}: \mathrm{N}$, though an inefficient one as activation at room temperature is mainly to the conduction band tail states. ${ }^{12}$

Field emission measurements were carried out using smooth mirror quality $a-\mathrm{C}: \mathrm{H}: \mathrm{N}$ films $n^{++}-\mathrm{Si}$ substrates as the cathode, and an ITO coated glass slide as the anode. The spacing and overlap between the plate anode and the cathode was set at $50 \mu \mathrm{m}$ (using glass fiber spacers) and $1 \mathrm{~cm}^{2}$. Field emission measurements were carried out at a pressure of $5 \times 10^{-7}$ Torr. The current density $(J)$ versus electric field 


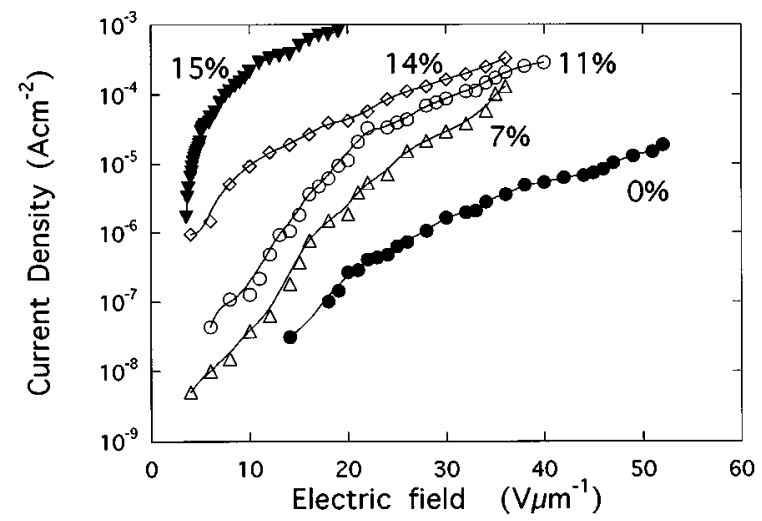

(a)

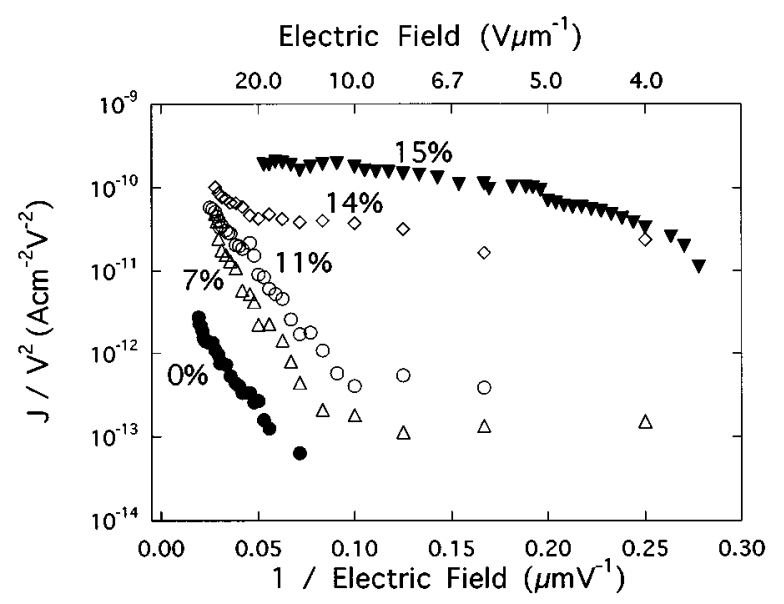

(b)

FIG. 1. Electron emission characteristics of $0.3 \mu \mathrm{m}$ thick (a)-(c):H:N films with varying $\mathrm{N}$ content. (a) Current density vs electric field (b) FowlerNordheim plots.

(E) plots from five $0.3 \mu \mathrm{m}$ thick $a-\mathrm{C}: \mathrm{H}: \mathrm{N}$ films with $\mathrm{N}$ contents of $0 \%, 7 \%, 11 \%, 14 \%$, and $15 \%$ are shown in Fig. 1(a). These characteristics are stable and repeatable over periods of weeks in the vacuum chamber. Exposure to atmosphere does not degrade the emission properties of the films. The current density is calculated by taking the entire film area to form the cathode (all values of current density are quoted in this basis). The electric field is that obtained by taking the entire applied voltage to be dropped across the vacuum gap. Control experiments were carried out using an uncoated $\mathrm{Si}$ substrate and by reversing the polarity of the anode-cathode terminals. No current could be measured up to a field of 50 $\mathrm{V} \mu \mathrm{m}^{-1}$ (the instrumentation was sensitive down to a current level of $10 \mathrm{nA}$ ). The nominal onset fields for an emission current density of $10^{-3} \mathrm{~mA} \mathrm{~cm}^{-2}$ from the data in Fig.

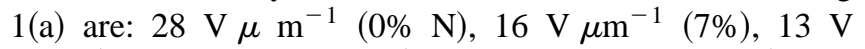

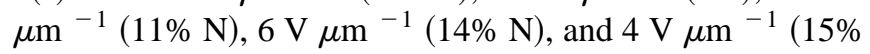
$\mathrm{N})$. The data plotted according to the Fowler-Nordheim $(\mathrm{F}-\mathrm{N})$ relationship for field emission, $\ln \left(J / V^{2}\right)=-b / E+\ln$ (a) is shown in Fig. 1(b). The $J-E$ data from the film with the highest $\mathrm{N}(15 \%)$, which has the lowest onset field shows a very good fit to a $J=\mathrm{eV}^{2}$-type relationship.

The emission barrier calculated assuming an ideal flat plate emitter from the $\mathrm{F}-\mathrm{N}$ plots for $0 \% \mathrm{~N}, 7 \% \mathrm{~N}$, and $11 \%$

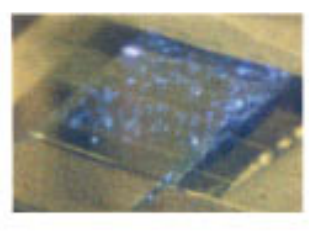

(a)

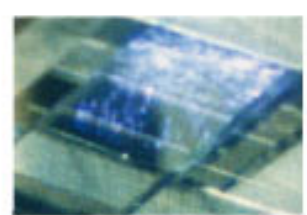

(b)

\section{$1 \mathrm{~cm}$}

FIG. 2. High current spot emission from an $a-\mathrm{C}: \mathrm{N}$ film on $n^{++}-\mathrm{Si}$ cathode (a) $0.1 \mathrm{~mA} \mathrm{~cm} \mathrm{~cm}^{-2}$ (b) $0.2 \mathrm{~mA} \mathrm{~cm} \mathrm{~cm}^{-2}$. The transparent ITO coated glass plate anode is separated from the cathode by three $50 \mu \mathrm{m}$ diam glass fibers in a vacuum of $5 \times 10^{-7}$ Torr. Fluorescence from the ITO occurs at local high current density spots.

$\mathrm{N}$ films all give values of $0.03-0.05 \mathrm{eV}$ in the high field region $\left(1 / E<0.1 \mu \mathrm{m} \mathrm{V}^{-1}\right)$. There is some justification in assuming an ideal flat plate emitter, AFM profiles before and after emission measurements on $0 \%, 7 \%$, and $11 \% \mathrm{~N}$ films show an unchanged minimum to maximum surface morphology $<3 \mathrm{~nm}$. However, extrapolation of the data using the calculated emission barrier gives an effective emission area of the order of $10^{-28}-10^{-29} \mathrm{~m}^{2}$ (whereas the entire cathode area is $10^{-4} \mathrm{~m}^{2}$ ). Furthermore, optical absorption measurements of the band gap of the $a-\mathrm{C}: \mathrm{H}: \mathrm{N}$ films gave values in the range of 1.7-2.1 eV, which, when taken together with photoelectron yield measurements, ${ }^{6}$ would give the films an electron affinity of $\cong 2 \mathrm{eV}$. The origin of the very low $0.05-$ $0.03 \mathrm{eV}$ emission barrier, therefore, cannot be directly related to any fundamental property of the $a-\mathrm{C}: \mathrm{H}: \mathrm{N}$ (as in the case of classical F-N emission from metal cathodes).

The ITO coated glass anode can also be used as a low persistence phosphor for imaging of the emission from the underlying cathode at high current density. ${ }^{15}$ At a current density below $10^{-2} \mathrm{~mA} \mathrm{~cm}^{-2}$ there is no glow from the ITO which is perceptible to the naked eye. As the current density approaches $5 \times 10^{-2} \mathrm{~mA} \mathrm{~cm}^{-2}$ there appears a uniform purple glow over the entire anode area which overlies the cathode. This uniform glow is weak and can only be seen in the dark. It appears, therefore, that at this level of current density there is uniform emission from the $a-\mathrm{C}: \mathrm{H}: \mathrm{N}$ film on $n^{++}-\mathrm{Si}$. When the current density rises above $8 \times 10^{-2} \mathrm{~mA}$ $\mathrm{cm}^{-2}$, bright spots begin to appear and the highest current emission occurs, preferentially, from a limited number of spots. Further increase of the electric field and current leads to the spots becoming brighter and a number of spots become unstable. The glow has a background of randomly moving spots due to emission sites turning on and off, together with emission spots which are stable over time periods of minutes. A typical image of bright emission spots, at a nominal current density of $0.1 \mathrm{~mA} \mathrm{~cm}{ }^{-2}$ (calculated over the entire cathode), is shown in Fig. 2(a). The emission from the same sample at a current density of $0.2 \mathrm{~mA} \mathrm{~cm}^{-2}$ is shown in Fig. 2(b). The three optical fiber spacers can be seen in Fig. 2(b) due to the enhanced emission caused by the field concentration around them. The nonuniformity in the gap introduced by the three fiber spacers is clearly seen from the much brighter glow between the top two fibers. The bright glow in this region includes of a number of "moving", 


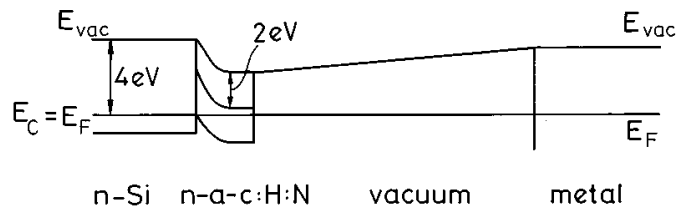

$$
E_{\text {vac }}
$$

(a)

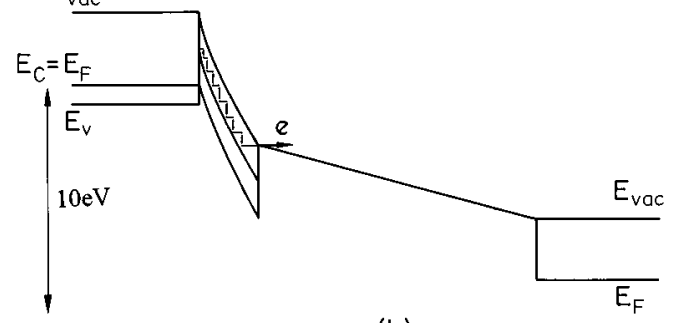

(b)

FIG. 3. Heterojunction band diagram of $n^{++}-\mathrm{Si} / a-\mathrm{C}: \mathrm{H}: \mathrm{N}(0.3 \mu \mathrm{m})$ vacuum $(1.5 \mu \mathrm{m}) /$ metal structure. The $a-\mathrm{C}: \mathrm{H}: \mathrm{N}$ is taken to have a dielectric constant of 4 and an electron affinity of $2 \mathrm{eV}$. The doping (donor) in the $a-\mathrm{C}: \mathrm{H}: \mathrm{N}$ is taken to be $3 \times 10^{16} \mathrm{~cm}^{-3}$. (a) No applied field top; (b) an applied voltage of $10 \mathrm{~V}$ between the anode and $n^{++} \mathrm{Si}$.

spots which have been integrated over the camera time of 3 $\mathrm{s}$. These pictures were taken in a normally lighted room.

To understand the origins of the emission process from $a-\mathrm{C}: \mathrm{H}: \mathrm{N}$ on $n-\mathrm{Si}$, we have considered a composite $n^{++}-\mathrm{Si}$ $a-\mathrm{C}: \mathrm{H}: \mathrm{N} / \mathrm{vacuum} / \mathrm{metal}$ energy band diagram (Fig. 3). The $\mathrm{Si}$ and the $a-\mathrm{C}: \mathrm{H}: \mathrm{N}$ should be viewed as forming a heterojunction. ${ }^{16}$ The $a$-C:H:N is taken to be the most $(15 \% \mathrm{~N}) n$-type with an electron affinity of $2 \mathrm{eV}$ and a thickness of $0.3 \mu \mathrm{m}$. It is assumed that there are no charged defect states at the heterojunction interface. The electron affinity of the $\mathrm{Si}$ and the anode metal are taken to be 4 and $3.7 \mathrm{eV}$, respectively (Fig. 3 is drawn to scale with a vacuum gap of $1.5 \mu \mathrm{m})$. The depletion region of $150 \mathrm{~nm}$ at an anode voltage of $0 \mathrm{~V}$ in the $a-\mathrm{C}: \mathrm{H}: \mathrm{N}$ is calculated using a dielectric constant of 4 , activation energy of $0.5 \mathrm{~V}$ (from measured refractive index and $J-T$ on the $15 \% \mathrm{~N}$ film) and assuming an ionized donor density of $3 \times 10^{16} \mathrm{~cm}^{-3}$ [Fig. 3(a)]. The donor density was assumed on the basis of the measured activation energy. The band diagram which arises if $10 \mathrm{~V}$ are applied between the $n^{++}-\mathrm{Si}$ and the metal anode (to give what would be viewed experimentally as a field of $\sim 7 \mathrm{~V} \mathrm{~m}^{-1}$ across the $1.5 \mu \mathrm{m}$ vacuum gap) is shown in Fig. 3(b). What is interesting to note is that with a charge density of $3 \times 10^{16} \mathrm{C} \mathrm{cm}^{-3}$ in the $a-\mathrm{C}: \mathrm{H}: \mathrm{N}$ there is a larger electric field across the $0.3 \mu \mathrm{m}$ thick film $\left(\cong 20 \mathrm{~V} \mu \mathrm{m}^{-1}\right)$ than what would have been expected across the vacuum gap in the case of a metal-vacuum-metal field emission configuration. With almost $6 \mathrm{~V}$ dropped across the $a-\mathrm{C}: \mathrm{H}: \mathrm{N}$ film, carriers which enter the $a-\mathrm{C}: \mathrm{H}: \mathrm{N}$ film at its conduction band edge by thermal excitation (or tunneling through interface states) from the Si and drift in the direction of the electric field, can lose up to $4 \mathrm{eV}$ in collisions and still remain close to the vacuum level at the $a$-C:H:N surface. The model suggests that hot electron emission from the fully depleted $a-\mathrm{C}: \mathrm{H}: \mathrm{N}$ layer can be the origin of the measured low onset field for emission. This has similarities to the hot electron model proposed by Bayliss and Latham ${ }^{17}$ for a metal cathode covered by a thinfilm insulator. With a semiconductor, the major difference is the distributed nature of the space charge and the ability to control the amount of band bending by varying the donor concentration.

The enhanced emission from $a-\mathrm{C}: \mathrm{H}: \mathrm{N}$ as the $\mathrm{N}$ content increases, can now be understood in terms of an increase in the concentration of ionized donor centers leading to a higher field across the films at a given applied voltage between the $n^{++}-\mathrm{Si}$ and the metal anode. [Figure 3(b) illustrates the experimental case with maximum concentration.] A consequence of this model is that the true cathode is the $n^{++}-\mathrm{Si}$ and that the $a-\mathrm{C}: \mathrm{H}: \mathrm{N}$ acts as, what we term, a "space charge interlayer" with a lower electron affinity to enhance electron emission.

Our results imply that although $a-\mathrm{C}: \mathrm{H}: \mathrm{N}$ films are successful in bringing about very low onset fields $\left(4 \mathrm{~V} \mathrm{~m}^{-1}\right)$ for field emission, the $1 \mathrm{~mA} \mathrm{~cm}{ }^{-2}$ current density required for diode-type field emission displays cannot be obtained uniformly and reliably. Additionally, the highest current density at the lowest field ( $a$-C:H:N with 15\% N) has been obtained from a film which shows a $\mathrm{V}^{2}$ current dependence. This is not appropriate for the switching of a display element, where an exponential increase in current is required to obtain sharp turn-on at a well-defined voltage. ${ }^{18}$ However, in a triode configuration, where the cathode can operate at lower current densities, $a-\mathrm{C}: \mathrm{H}: \mathrm{N}$ has a great potential as a thin-film cathode interlayer for reduction of the emission field.

${ }^{1}$ I. Brodie, Proc. IEEE 82, 1006 (1994), and references therein.

${ }^{2}$ F. J. Himpsel, J. A. Knapp, J. A. Van Vechten, and D. E. Eastman, Phys. Rev. B 20, 624 (1979).

${ }^{3}$ B. B. Pate, Surf. Sci. 165, 83 (1986).

${ }^{4}$ M. W. Geis, J. C. Twichell, J. Macaulay, and K. Okano, Appl. Phys. Lett. 67, 1328 (1995).

${ }^{5}$ J. Robertson, Abstracts Inst. Phys., Condensed Matter and Materials Phys. Meeting, December, 1994, Warwick, UK.

${ }^{6}$ J. Schafer, J. Ristein, and L. Ley, J. Non. Cryst. Solids 166-164, 1123 (1993).

${ }^{7}$ S. Bagic and R. V. Latham, J. Phys. D 21, 200 (1988).

${ }^{8}$ J. D. Shovlin and M. E. Kordesch, Appl. Phys. Lett. 65, 863 (1994).

${ }^{9}$ K. Okano and K. K. Gleason, Electron. Lett. 31, 74 (1995).

${ }^{10}$ N. Kumar, H. R. Schmidit, M. H. Clark, A. Ross, B. Lin, L. Fredin, B. Baker, C. Xie, C. Hilbert, R. L. Fink, C. N. Potter, A. Krishnan, and D. Elchman, Society for Information Display, SID 94 Digest, p. 43, 1994.

${ }^{11}$ V. S. Veerasamy, J. Yuan, G. A. J. Amaratunga, W. I. Milne, K. W. R. Gilkes, M. Weiler, and L. M. Brown, Phys. Rev. B 48, 8016 (1993).

${ }^{12}$ S. R. P. Silva and G. A. J. Amaratunga, Thin Solid Films 270, 194 (1995).

${ }^{13}$ J. Robertson and C. A. Davies, Diam. Relat. Mater. 4, 441 (1995).

${ }^{14}$ S. R. P. Silva, K. J. Clay, S. P. Speakman, and G. A. J. Amaratunga, Diam. Relat. Mater. 4, 977 (1995).

${ }^{15}$ N. S. Xu, R. V. Latham, and Y. Tzeng, Electron. Lett. 29, 1596 (1993).

${ }^{16}$ G. A. J. Amaratunga, D. E. Segal, and D. R. McKenzie, Appl. Phys. Lett. 59, 69 (1991).

${ }^{17}$ K. H. Bayliss and R. V. Latham, Proc. R. Soc. A 403, 285 (1986).

${ }^{18} \mathrm{~N}$. Kumar (private communication). 